\title{
Incontinence in women: different response rates may introduce bias in community studies of pad consumption
}

\author{
Hogne Sandvik, Steinar Hunskaar
}

Epidemiological surveys will be biased if subgroups of patients are over-represented among non-responders. Severe urinary incontinence may be associated with debilitating morbidity which renders cooperation impossible. Under such circumstances even a response rate of $90 \%$ may be too low to ensure valid prevalence estimates. ${ }^{1}$ To elucidate this problem we conducted a survey among incontinent women who used pads. The design enabled us to outline the response patterns of incontinent women of different ages and with different severity of incontinence.

Methods: The study was conducted in Bergen and two neighbouring rural municipalities in western Norway. In Norway incontinence pads are prescribed by doctors, and paid for by the national insurance. Together with the invoices, local insurance offices receive detailed information on all such sales.

During one year (October 1992-93) we registered data on sales to all women living in the study area. Individual consumption of pads was calculated as the number of pads sold (not counting the latest sale), divided by the number of days between the first and latest sales date. Since most patients used more than one type of pad, the mean pad weight was calculated by dividing total pad weight by the total number of pads. A concept of "total pad use" (daily consumption $\times$ mean pad weight) was also defined.

After computerised randomisation in six age strata (between 20 and 89 years) an introductory letter was sent to a sample of the women. In this letter it was explained how we had obtained information about their incontinence, and that we were interested in learning more about their experiences. The women were asked to return a signed copy of the letter, stating whether they would consent to an interview in their own home. The study was approved by the Norwegian Data Inspectorate and the regional ethical committee.

Results: Introductory letters were sent to 401 women, of whom 202 responded (50\%). Six of those who responded denied having urinary incontinence and 43 declined to participate.

The willingness to participate was highest among middle aged women $-50 \%$ at ages 50 69 years, with $44 \%$ at $70-79$ years, $37 \%$ at 40 49 years, and $26 \%$ at ages $20-39$ and $80-89$. Middle aged women were also perfectly representative with regard to total pad use. The young and old, however, constituted a selected sub-
Representativeness of those willing to participate with regard to median total pad use (g/day, $95 \%$ CI). Total pad use could be calculated for 343 patients

\begin{tabular}{lrcrll}
\hline & All & & \multicolumn{2}{l}{ Willing to participate } \\
\cline { 2 - 3 } $\begin{array}{l}\text { Age groups } \\
(y)\end{array}$ & No & $\begin{array}{l}\text { Total pad use } \\
\text { median }(95 \%\end{array}$ & CI $)$ & No & $\begin{array}{l}\text { Total pad use } \\
\text { median }(95 \% \text { CI })\end{array}$ \\
\hline $20-39$ & 44 & $104(45-226)$ & 10 & $20(8-45)$ \\
$40-79$ & 210 & $31(27-42)$ & 98 & $32(26-51)$ \\
$80-89$ & 89 & $61(48-99)$ & 25 & $48(19-63)$ \\
\hline
\end{tabular}

sample with lower consumption (table). In this comparison the age groups 40-79 years were treated as one group, since total pad use was stable in these groups.

Discussion: Although pad use may reflect perceptional differences and as such be a measure of personal hygiene, there is little doubt that pad use is most prevalent among severely incontinent women. ${ }^{2}$

The overall response rate in this study was 50 , which is low compared with most epidemiological surveys. ${ }^{2-5}$ The target population in the present study was, however, restricted to incontinent women only. The lower overall response rate among these women indicates that incontinent women will be over-represented among non-responders in epidemiological surveys.

Many authors have reported that there is a prevalence peak for female urinary incontinence in mid-life..$^{3-5}$ This peak is not reflected in the use of pads, however, possibly due to less severe incontinence in middle aged women. ${ }^{5}$ However, middle aged women with incontinence respond more readily to inquiries about this condition (figure), and the more severely incontinent young and old women may not be included (table), probably because of accompanying debilitating morbidity.

This study indicates that the prevalence of severe urinary incontinence will be underestimated in epidemiological surveys. Response bias may contribute to a prevalence peak in mid-life.

1 Cartwright A. Health surveys in practice and in potential: a critical review of their scope and methods. London: King critical review of their scope and methods.

2 Burgio KL, Matthews KA, Engel BT. Prevalence, incidence and correlates of urinary incontinence in healthy, middleand correlates of urinary incontinence

3 Thomas TM, Plymat KR, Blannin J, Meade TW. Prevalence of urinary incontinence. BMF 1980;281:1243-5.

4 Fall M, Frankenberg S, Frisén M, Larsson B, Petrén $M$. 456000 Swedes may have urinary incontinence. Only every fourth person seeks help for the disorder (In Swedish). Läkartidningen 1985;82:2054-6.

5 Sandvik H, Hunskaar S, Seim A, Hermstad R, Vanvik A, Bratt $H$. Validation of a severity index in female urinary incontinence and its implementation in an epidemiological survey. F Epidemiol Community Health 1993;47:497-9. 